\title{
O SUS E A MUNICIPALIZAÇÃO À LUZ DA EXPERIÊNCIA CONCRETA
}

\begin{abstract}
Aparecida Linhares Pimenta *
RESUMO: A maneira como cada Município brasileiro entendeu e assumiu as novas atribuições em relação à Saúde, previstas na Constituição de 1988, foi extremamente diversificada, e dependeu de vários fatores, entre eles a experiência com as mudanças mais recentes vividas pela saúde no Brasil, ou seja: as Ações Integradas de Saúde - AIS e o Sistema Unificado e Descentralizado de Saúde - SUDS. Faremos uma breve análise das AIS e do SUS o que, a nosso ver, facilitará a análise de implantação do SUS e a municipalização. Esta análise tem como referência básica a experiência vivida em uma Prefeitura Municipal, que se empenhou profundamente no sentido de assumir a responsabilidade de promover e cuidar da saúde de seus municipes.
\end{abstract}

\section{AÇÕES INTEGRADAS DE SAÚDE - AIS}

O Plano das Ações Integradas de Saúde propunha-se, no discurso, a integrar os serviços públicos de saúde, descentralizar o sistema de assistência médica, e criar uma "porta de entrada" para o sistema através de uma rede básica de serviços de saúde. Para tanto, propunha-se a regionalização do sistema e o gerenciamento, através de órgãos colegiados interinstitucionais, com a participação da comunidade usuária dos serviços. Assim, teríamos as

* Atualmente Secretária Municipal de Saúde do Município de Santos, ex-Secretária Municipal de Saúde do Município de Baurú, ambos do Estado de São Paulo. 
Comissões Municipais, as Regionais e uma Estadual, responsável pela coordenação da política de saúde a nível de cada Estado da Federação. O nível federal teria a Comissão Interinstitucional de Planejamento, formada pelos quatro ministérios envolvidos diretamente com o setor saúde: Ministério da Previdência e Assistência Social, representado pelo INAMPS; Ministério da Saúde, Ministério da Educação e Ministério do Trabalho. Este último tem assento na CIPLAN em função de sua responsabilidade pelas ações relacionadas com a saúde dos trabalhadores.

No que diz respeito ao financiamento, propunha-se um redirecionamento de repasses de recursos da Previdência para as Secretarias Estaduais e Municipais de Saúde, em detrimento dos repasses para a iniciativa privada. Estes repasses dar-se-iam mediante a assinatura de Convênios Interinstitucionais.

Embora o discurso oficial do governo fosse de que as AIS estavam sendo implantadas com o objetivo principal de integração/descentralização, na realidade elas se constituíram principalmente em uma estratégia de expansão de cobertura a baixo custo, cobertura esta que deveria realizar-se através da recuperação da capacidade instalada ociosa dos serviços estaduais e municipais da saúde.

Neste sentido, é importante frisar que houve no Brasil, nas últimas duas décadas, um processo de esvaziamento econômico e político do poder local, o que levou a maioria dos 4500 municípios brasileiros, e mesmo dos Estados, a se atrofiarem e tornarem-se incapazes de enfrentar os problemas básicos dos municípios, incluindo-se aí os relacionados com a situação de saúde da maioria da população. 
Assim, as Ações Integradas de Saúde que propunham descentralização teriam, para realmente obter éxito, que contar com um aporte significativo de recursos para que os governos municipais pudessem assumir integralmente a proposta de expansão de cobertura, numa lógica que rompesse com a dicotomia entre prevenção e cura, e fosse capaz, na prática, de integrar ações de caráter coletivo com ações de caráter individual.

Além disso, as AIS não conseguiram romper com a visão privativista da saúde. Ao contrário, estes convênios reproduziram na rede pública as relações distorcidas de estímulo à produtividade próprias da rede privada na medida em que utilizavam, para efeitos de repasse de recursos, os mesmos parâmetros de pagamento ao setor privado, valorizando as ações individuais e curativas, e descuidando completamente das ações coletivas e da qualidade do atendimento.

Com isso, a implantação das AIS vai depender muito das realidades regionais e municipais. Assim, naqueles municípios que já possuíam experiência acumulada na organização de serviços de saúde, as AIS se implantaram de maneira bastante distinta daqueles que não possuíam nenhum serviço de saúde próprio no nível municipal. Entre os primeiros, encontram-se inúmeros municípios brasileiros que conseguiram eleger governos municipais progressistas nas eleições de 1976, como é o caso de Londrina, Campinas, Montes Claros, Lages, Piracicaba, Niterói e outros, e nas eleições de 1982, como é o caso de Itú, Campinas, Baurú, Cambé, Uberlândia, Cuiabá e outros. Esses municípios lograram, apesar de toda a escassez de recursos, desenvolver experiências locais na área da saúde, de tal maneira que o convênio AIS representou um aporte adicional de recursos financeiros, e uma maior possibilidade de articulação 
interinstitucional entre as agências públicas prestadoras de serviços de saúde no âmbito de cada município.

No entanto, os recursos financeiros destinados pela Previdência Social às AIS são totalmente secundários dentro do quadro geral de gastos com assistência médica. Assim, segundo dados do INAMPS, as Ações Integradas de Saúde representaram, no ano de 1985, menos de $10 \%$ do orçamento destinado à assistência médica previdenciária. Enquanto isso, neste mesmo ano, o setor privado abocanhou $49 \%$ do orçamento total do INAMPS. Ou seja, apesar do discurso oficial, a lógica privativista continuou sendo determinante.

Importante registrar que as AIS são implantadas durante o primeiro ano da chamada Nova República que conta, no nível do aparelho de Estado, com um número significativo de intelectuais oriundos do movimento oposicionista surgido durante os anos de ditadura.

No caso do setor saúde vamos ter toda a cúpula que dirige o INAMPS formada por uma parcela do chamado "movimento sanitário", de âmbito nacional e que envolveu praticamente todas as áreas de profissionais da saúde, conquistando associações e sindicatos, que penetrou nas Comissões de Saúde do poder legislativo, nos sindicatos dos trabalhadores através da criação dos Departamentos Sindicais de Saúde do Trabalhador, e que mobilizou parte da Universidade, da Igreja, atingindo até mesmo alguns movimentos sociais urbanos, que se organizaram em torno da luta por melhores serviços de saúde. Este movimento, cujo lema era "Saúde e democracia", conseguiu criar um debate nacional sobre a necessidade de reformulação do Sistema de Saúde e contra a mercantilização da medicina. 
Assim, a Nova República consegue cooptar parte destes quadros para o aparelho de estado, o que vai, de certa maneira, facilitar a implantação das AIS já que, do ponto de vista jurídico/institucional, o "movimento sanitário" defendia as mesmas propostas contidas nas AIS. Parte deste "movimento sanitário" manteve uma posição de crítica à Nova República, por acreditar que para romper com a lógica privativista do Sistema de Saúde era necessário buscar articular um bloco contra-hegemônico, mais amplo que as forças da Aliança Democrática, que davam sustentação ao Governo Sarney.

De 1985 a 1987 ocorre progressivamente um fortalecimento das Ações Integradas de Saúde, com adesão de praticamente todos os Estados e suas capitais, e de um grande número de municípios.

Mas à medida que avança o processo das AlS manifesta-se, com maior nitidez, os limites desta forma de organização dos serviços. A tão propalada "descentralização" não passa de linguagem, visto que o nível local, no caso os governos municipais, continua a ocupar papel totalmente secundário na definição da política de saúde, à medida em que cada uma das diferentes instituições públicas existentes no setor continua funcionando com dinâmica própria, dependendo da "boa vontade" dos dirigentes locais destas instituições trabalhar de forma integrada, ou não.

Em função destas dificuldades inicia-se, em 1987, a discussão sobre a necessidade de avanços no sentido da descentralização do INAMPS, com transferência de recursos e responsabilidades para os Estados e Municípios, e de superação da forma de pagamento por produtividade. Há neste momento coincidência de interesses entre Estados e Municípios, que sofriam diariamente as conseqüências deste tipo de convênio, e a cúpula do INAMPS, que reconhecia a ineficiência da União diante dos problemas do setor. 
Do ponto de vista político há interesse dos governadores dos Estados em avançar o processo de descentralização do INAMPS, pois isto representava ter mais poder na área da saúde, visto ser esta a única instituição que realmente possuía recursos financeiros. Por outro lado, acentuam-se as divergências entre o governo federal e os governos estaduais, o que provoca a necessidade de tomar medidas institucionais que consolidem mais a descentralização.

A Nova República vive um momento bastante distinto. Em fevereiro de 1986 o Governo Sarney implanta a Reforma Econômica, conhecida popularmente como "Plano Cruzado", com desvalorização brutal da moeda nacional e congelamento de preços e salários, com o objetivo de conter a inflação. Estas medidas encontraram amplo apoio popular até porque representaram um aumento do poder aquisitivo das classes trabalhadoras. 0 Governo Sarney e as forças da Aliança Democrática vivem, neste ano, seu período de auge. Como conseqüência, em novembro de 1986, os partidos da Aliança Democrática - Partido do Movimento Democrático Brasileiro (PMDB) e Partido da Frente Liberal (PFL) - conseguem vencer as eleições para governadores na absoluta maioria dos Estados brasileiros.

No entanto, 10 dias após as eleições, o Governo Federal suspende o congelamento dos preços traindo os compromissos assumidos com o povo, e realizando o que, a nosso ver, pode ser considerado como uma das maiores fraudes eleitorais da história da República. A inflação volta rapidamente a patamares elevadíssimos, e no ano de 1987 há um aprofundamento da crise econômica e social que atinge todo o país. A Nova República vai assumindo posições cada vez mais conservadoras e anti-populares.

Com estas mudanças, ocorridas no nível do Governo Federal, a cúpula do INAMPS começa a sentir a fragilidade das AIS e a necessidade de consolidar 
juridicamente a proposta de descentralização. Para isto, vai contar com o apoio de boa parte dos governadores dos Estados, agora assumindo posições políticas bastante contraditórias com relação ao Governo Federal.

Com o desastre na condução da política econômica levada a cabo pelo Governo Sarney após o Plano Cruzado, os governadores dos Estados começam a distanciar-se do mesmo, pois apoiá-lo significava assumir a coresponsabilidade por um Governo que alcançou alto índice de impopularidade. No entanto, este distanciamento não representava rompimento, à medida em que os partidos da Aliança Democrática, que eram os mesmos dos governadores, continuavam detendo a absoluta maioria dos Ministérios que, em última instância, eram as forças que determinavam as políticas nacionais, tanto a econômica como as políticas sociais.

$E$, portanto, dentro deste clima de instabilidade e incertezas, o Ministério da Previdência e Assistência Social, através do INAMPS, propõe, em 1987, um reordenamento do sistema de saúde e em julho de 1987, através de um Decreto Presidencial, é criado o Sistema Unificado e Descentralizado de Saúde - SUDS.

SISTEMA UNIFICADO E DESCENTRALIZADO DE SAÚDE - SUDS

O SUDS constitui-se num aprofundamento das AIS, e representa um avanço em relação à descentralização - unificação à medida em que propunha a "estadualização" do INAMPS, ou seja, que as Secretarias Estaduais de Saúde assumissem efetivamente todas as funções deste órgão. Com isto descentralizase até os Estados, o que antes estava no nível federal, unificam-se as estruturas regionais do INAMPS com as estruturas estaduais, e criam-se as condições 
objetivas para que a política de saúde no nível de cada Estado tenha um comando único.

Outro avanço do SUDS com relação às AIS consistiu na sua forma de financiamento, que deixa de ser por produção de serviços e passa a ser feita mediante a orçamentação de um Plano Diretor, que deveria incluir, a partir da base, as realidades municipais, regionais e estaduais. Os municípios, portanto, passam a "aderir" aos SUDS-Estaduais, e não mais ao INAMPS, como no Convênio das AIS.

Assim como as AIS, o SUDS também teve sua implantação sujeita às realidades locais e às disputas políticas dentro do aparelho do Estado. Não só a "estadualização" do INAMPS, como também a "municipalização" dos serviços básicos de saúde (que é um dos objetivos do SUDS), se deram de maneira extremamente diversificada. Se analisarmos o SUDS no nível nacional, e os anos de 87 e 88, vamos encontrar um verdadeiro mosaico: há desde Estados que assumiram integralmente a estrutura do INAMPS, e municipalizaram grande parte de sua rede básica, como é o caso de São Paulo; até Estados em que as estruturas do INAMPS continuaram não só realizando as mesmas ações, como mantendo o convênio das AIS com o INAMPS.

Um dos fatores que contribuíram para o sucesso do SUDS em alguns Estados foi a experiência acumulada das AIS, associada à existência de estruturas regionalizadas da Secretaria Estadual de Saúde. Estas estruturas assumiram, em conjunto com os municípios, a atribuição de elaboração do Plano Diretor, que exigia um diagnóstico mínimo da realidade de cada município, bem como a definição de algumas prioridades para a área da saúde. Este processo foi muito rico nos municípios que já contavam com alguma experiência na 
organização de serviços e pode, em conjunto com estas regionais, buscar soluções viáveis para os problemas de saúde da população.

Um fator limitante do SUDS consistiu na falta de uma política de financiamento por parte do INAMPS capaz de atender à demanda dos Estados e municípios, num período em que a inflação atingia níveis elevadíssimos e corroía, de maneira sistemática, os repasses mensais que, em geral, não eram "corrigidos". Por outro lado, o setor privado da medicina continuava tendo papel preponderante no sistema de captação de recursos, e exercendo toda sorte de pressão no sentido de inviabilizar o SUDS.

As relações entre os governos estaduais e municipais também eram bastante complicadas. O SUDS propunha a "municipalização" dos serviços básicos de saúde, ou seja, que os governos municipais passariam a gerenciar os serviços estaduais e receberiam recursos financeiros para custearem parte de seus serviços próprios. Também neste caso a realidade de cada município determinou o grau de implantação da descentralização/integração, reproduzindose no nível dos municípios o mesmo mosaico citado anteriormente. Também em relação à escassez de recursos financeiros, e à inexistência de uma política de repasse que, pelo menos, corrigisse a inflação, os governos municipais enfrentaram grandes dificuldades. Uma delas foi que os recursos para investimentos no setor, ao contrário dos recursos para custeio, dependiam de negociações político-partidárias entre os governos estaduais e municipais, com discriminação evidente dos municípios que não eram do mesmo partido do governo do Estado.

Apesar destas limitações, o SUDS representou, de fato, um dinamismo dos serviços públicos de saúde em alguns Estados, registrando-se 
extensão da cobertura com expansão para as camadas mais carentes da população, e uma tentativa de implantar programas de alcance coletivo.

Não obstante, muitas distorções do Sistema de Saúde permanecem com o SUDS: continuam existindo dois Ministérios, sendo que em alguns Estados conseguiu-se diminuir o peso das estruturas do INAMPS; e, embora o controle do setor privado da medicina tenha passado pelas Secretarias Estaduais de Saúde a lógica mercantilista continua tendo papel determinante dentro do Sistema.

\section{SISTEMA ÚNICO DE SAÚDE - SUS}

Em março de 1986 realizou-se em Brasília a $8^{*}$ Conferência Nacional de Saúde - $8^{a}$ C.N.S. - que foi precedida por um amplo processo de discussão ocorrido nacionalmente, envolvendo milhares de pessoas através das préConferências Estaduais, realizadas em 23 Estados da Federação.

A $8^{a}$ C.N.S. contou com a participação de cerca de 4000 pessoas, entre as quais 1000 delegados e representantes de instituições de saúde e da sociedade civil organizada.

As finalidades da $8^{a}$ C.N.S., de acordo com seu Regimento, eram: contribuir para a reformulação do Sistema Nacional de Saúde e proporcionar subsídios para a Assembléia Nacional Constituinte.

A $8^{a}$ C.N.S. aponta para a garantia da saúde como direito inerente à cidadania; e em relação à organização dos serviços propõe: descentralização da gestão; integralidade das ações; regionalização e hierarquização; participação da 
comunidade e fortalecimento do município. Em relação ao financiamento propõe a criação dos Fundos Únicos de Saúde - federal, estadual e municipal - geridos com participação da comunidade; e pré-fixação de um percentual mínimo sobre as receitas públicas, sendo que o Estado deveria financiar integralmente o setor, e os recursos da Previdência deveriam destinar-se exclusivamente para custear o seguro social dos trabalhadores.

Em 1987 é instalada a Assembléia Nacional Constituinte, e 19 meses depois, em outubro de 1988 é aprovada a nova Constituição Federal, em substituição à Constituição de 1967, promulgada pelo regime autoritário.

A nova Constituição, que contem cinco artigos referentes à saúde no capítulo da Seguridade Social, representa avanços significativos em relação à Constituição de 1967 no que diz respeito ao setor.

As propostas da $8^{*}$ C.N.S. são contempladas, em linhas gerais, com exceção do financiamento: na nova Constituição estabelece-se o custeio da saúde com recursos da Seguridade Social, da União, dos Estados e Municípios, sem definir pré-fixação dos recursos dos três níveis de governo.

Durante os anos de 1989 e 1990 não ocorre nenhuma mudança no funcionamento do Sistema de Saúde, que continua operando nos moldes do SUDS, com assinatura de convênios de "municipalização", repasse de recursos financeiros através dos Termos Aditivos, sempre com valores defasados e atrasados, e gerenciamento através dos órgãos colegiados (CIMS, CRIS, CIS). No entanto, neste período ocorre uma ampla discussão sobre as Constituições Estaduais e as Leis Orgânicas dos Municípios. No Estado de São Paulo, tanto a constituição Estadual como a absoluta maioria das Leis Orgânicas Municipais foram bastante progressistas, já que se conseguiu uma ampla divulgação da 
proposta da Associação Paulista de Secretarias Municipais de Saúde, e os Municípios assumiram as propostas da Associação.

Neste mesmo período trava-se a batalha, no Congresso Nacional, para regulamentar o SUS através de leis que garantam a implantação das diretrizes da Constituição. E no final de 1990, com alguns vetos, o então presidente Fernando Collor homologa as Leis 8080 e 8142, denominadas Leis Orgânicas da Saúde.

A partir do final de 1990, e principalmente em 1991, vários municípios realizam suas primeiras Conferências, com formação dos Conselhos Municipais de Saúde. No Estado de São Paulo quase a totalidade dos municípios já têm assinado o convênio de municipalização.

Em 1991 vamos ter municípios já assumindo várias atribuições, antes de competência do Estado, como é o caso das ações de vigilância sanitária e saúde do trabalhador, gerência dos PAMs; e com Conselhos e Fundos Municipais dando seus primeiros passos.

Mas vai ser no início de 1991 que todo o sistema sofre um profundo golpe no que diz respeito ao financiamento. O INAMPS, que pela legislação do SUS deveria ser extinto, é o órgão que detém a quase totalidade dos recursos federais de saúde. E no início de 1991 elabora a Norma Operacional Básica $n^{\circ} 1$, que estabelece a nova sistemática de repasse de recursos para Estados e Municípios, através do pagamento por produção de serviços. Esta norma exige que os Estados e Municípios assinem convênios para receberem por produção, para isto estabelecendo alguns critérios, tais como ter Conselhos e Fundos de Saúde, ter Plano de Carreira e outros. Com esta Norma os Municípios passam a ser tratados como meros prestadores de serviços, e as ações são remuneradas 
de acordo com as prioridades definidas pelo próprio INAMPS. Passamos - os Secretários Municipais de Saúde - a viver a chamada "ditadura da tabela", com uma total distorção de toda a proposta de o município assumir a gestão do Sistema de Saúde no nivel local: as ações melhor remuneradas pela tabela são exatamente aquelas que envolvem alta tecnologia e são de caráter curativo e individual, sendo as ações coletivas mal remuneradas, ou até mesmo não remuneradas.

Neste período ocorre também, no caso de São Paulo, uma retração nos investimentos do Governo Estadual para as redes municipais $e$ municipalizadas. Com o avanço da municipalização das redes estaduais, a Secretaria de Estado da Saúde deixa de financiar o custeio de medicamentos e outros insumos da rede, mantendo exclusivamente o pagamento de pessoal, e ainda assim com salários bastante baixos. Desta forma os municípios passam a contar somente com recursos do próprio orçamento e o pagamento pelo INAMPS de faturas dos serviços produzidos.

Enquanto isto, a rede privada contratada pelo INAMPS, que recebe da mesma forma que o setor público, não tem nenhuma subordinação aos municípios. Em alguns Estados, o controle desta rede passa para as Secretarias Estaduais. Mas a sistemática de remuneração através das Autorizações de Internações Hospitalares - AlHs - é semelhante ao pagamento dos serviços ambulatoriais, que classifica os Estados e estabelece "tetos", através da chamada Unidade de Cobertura Ambulatorial - a UCA. Assim, de gestor do sistema o municipio limita-se a gestor da rede municipal e municipalizada, e remunerado da mesma forma que o setor privado contratado. Com isto toda a rede hospitalar existente nos municípios, que na sua maioria é contratada, não se incorpora ao sistema, fazendo com que vivenciemos uma situação totalmente 
anômala. Mesmo nos municípios onde houve um avanço no processo de participação popular e controle social, os Conselhos só podem acompanhar a política de saúde sob controle municipal, pois não tem sequer acesso às informações destes hospitais.

Além disso, é neste período que ocorre um processo crescente de descredenciamento dos hospitais. Insatisfeitos com os valores pagos pelo INAMPS, deixam de oferecer serviços aos usuários do SUS, agravando enormemente a situação da assistência hospitalar em todo o país.

Não só as limitações dos municípios em assumirem as novas atribuições previstas na Constituição e nas Leis do SUS vão dificultar o processo de municipalização, como principalmente a forma como o Governo Federal e a maioria dos Estados resistiram e boicotaram a descentralização.

A descentralização significa um processo em sentido contrário ao processo político vivido historicamente no país nas últimas décadas, que foi centralização e concentração do poder nas mãos do Governo Federal. E no caso do sistema de saúde, a descentralização deve apontar para a municipalização. Isto porque num país com as dimensões do Brasil, os governos estaduais não têm condições de assumirem de fato a gestão de um sistema composto de realidades locais extremamente diferenciadas. A estadualização pode reproduzir no nível de cada Estado as mesmas distorções antes centralizadas nos organismos federais.

A municipalização da saúde pressupõe o fortalecimento do poder local, tanto do ponto de vista financeiro como institucional, criando as bases para que os governos municipais tenham autonomia para gestão de suas políticas sociais. No entanto, a municipalização só representará avanço em termos de 
democratização da saúde se vier acompanhada da ampliação dos espaços de participação popular e controle social. Um dos pressupostos básicos para vencermos as dificuldades por que passa a saúde hoje no país é rompermos o autoritarismo do Estado brasileiro e a privatização da coisa pública. Neste sentido, a municipalização oferece melhores condições de controle social, pois o poder local, por estar mais próximo da população, por ter mais visibilidade, é mais suscetível à participação popular. Por outro lado, tem melhores condições de conhecer a realidade local e, portanto, encontrar as melhores soluções para os problemas detectados.

Infelizmente todo este processo de descentralização / municipalização vem ocorrendo num período tão adverso da vida política brasileira que fica difícil perceber os avanços alcançados em inúmeras cidades brasileiras. Basta lembrar que ele ocorre durante os governos Sarney e Collor, e convive com uma das maiores crises de miséria e recessão econômica. Os grandes desafios que um processo deste porte necessariamente traria acabaram sendo considerados secundários diante das sucessivas crises que abalaram a saúde dos brasileiros.

Nós, dirigentes municipais, ao invés de empenharmos todas as nossas energias no sentido de revertermos o modelo assistencial centrado no pronto atendimento, fomos obrigados a centrarmos nossos esforços na luta por recursos financeiros que impedissem o colapso total da assistência à saúde no país. Em conseqüência, ao invés de já estarmos hoje com experiência acumulada na organização de equipes interdisciplinares comprometidas efetivamente com os usuários, estamos ainda lutando para ter o controle do setor privado contratado. Ao invés de discutirmos em nossos Conselhos Municipais formas mais efetivas de controle social e participação dos municípios nas instâncias Estadual e 
Federal, estamos lutando pela instalação do Conselho Estadual de Saúde, isto num dos Estados mais avançados do país, que é São Paulo.

As adversidades que enfrentamos durante este período foram gigantescas, e exigiram muita vontade política para continuarmos lutando pela construção de sistemas locais de saúde verdadeiramente públicos, democráticos e resolutivos. E existem experiências concretas em várias cidades brasileiras demonstrando que a municipalização pode representar melhoria efetiva na qualidade de vida dos cidadãos. E são estas experiências que nos dão força para continuarmos lutando, luta esta que significa não só participação em um governo municipal que oferece condições de fazer avançar este processo, mas participando também de um movimento que congrega e organiza os municípios paulistas na luta pela implantação do SUS no nível municipal.

\section{REFERÊNCIAS BIBLIOGRÁFICAS}

1. BERLINGER, G.; TEIXEIRA, S.M.F.; CAMPOS, G.W. de S. Reforma sanitária: Itália e Brasil. São Paulo, HUCITEC, 1988. (Série Saúde em Debate).

2. CAPISTRANO FILHO, D. \& PIMENTA, A.L. Saúde para todos: um desafio do municipio. São Paulo, HUCITEC, 1988

3. CONFERÉNCIA NACIONAL DE SAÚDE, 8*, Brasília, 1986. Anais. Brasília, Ministério da Saúde, 1986. 